\title{
Conservative Management of Pott's Puffy Tumor: A Case Report
}

\author{
Sneha Konda ${ }^{1 *}$ and James Bradley White ${ }^{2}$ \\ ${ }^{1}$ Texas A \& M College of Medicine, USA \\ ${ }^{2}$ Texas Brain \& Spine Institute, Bryan, USA
}

Submission: February 15, 2017; Published: March 23, 2017

*Corresponding author: BSneha Konda BS, Texas A \& M College of Medicine, Temple, Texas, USA, Email: skonda@medicine.tamhsc.edu

\section{Abstract}

Introduction: Pott's Puffy tumor is an uncommon clinical entity that typically presents in adolescents as a complication of acute sinusitis MR and CT imaging is used to diagnose condition and detect severity/progression into intracranial complications such as abscess formation, thrombosis and meningitis. Surgical intervention is typically essential followed by broad-spectrum antibiotic therapy.

Case Presentation: A teenage male presented to the emergency room with progression of sinus and eye pain to severe orbital cellulitis with empyema over a span of 4 days. Imaging studies were conducted, showing significant infection of frontal sinuses. Patient received two surgical endoscopic surgeries, after which symptoms resolved gradually with strict antibiotic therapy and regular follow ups/MRI scans to detect any progression of condition. Patient remained neurologically intact with improvement of prior symptoms, forgoing the need for craniotomy.

Discussion: This clinical encounter illustrates that this condition may be managed with minimal surgical intervention if diagnosis is prompt, sinus drainage is definitive and early, and antibiotic therapy is aggressive and ongoing.

\section{Introduction}

Pott's Puffy tumor is a relatively rare clinical phenomenon, and manifests primarily as a non-neo plastic complication of acute frontal sinusitis. It is mainly characterized by subperiosteal abscess associated with osteomyelitis of the frontal bone, sometimes also the mastoid bone, resulting in its main key physical characteristic, frontal/forehead swelling. It can also result from, albeit much less commonly, trauma, drug abuse, and craniotomy $[1,2]$. Patients with this condition initially present with frontal sinusitis, developing into erythematous periorbital or scalp swelling (usually in the mid forehead region). Accompanying symptomology may include headache, fever, and rhinorrhea. Focal neurologic deficits and signs of elevated intracranial pressure may also be present $[3,4]$.

It is most prevalent in adolescents, due to higher incidence of URIs and subsequent plausible higher risk of acute bacterial sinusitis in this age group, although it can be seen across all ages [1]. Only about $0.5-2 \%$ of all URIs lead to bacterial sinusitis, and Pott's Puffy tumor is a rare complication of acute frontal sinusitis [5]. No reliable incidence figures are available. This condition is usually not seen before age 6 since maturation and pneumatization of frontal sinuses above orbital ridges does not occur until this age [6].
Pott's Puffy tumor was originally described in 1768 by British Surgeon Sir Pervical Pott as an abscess formation and extradural empyema as a result of trauma to the frontal bone, and subsequent osteomyelitis of the bone [7]. Infectious agents and bacterial species that are frequently responsible for the initial chronic sinusitis and ultimately the condition are as follows: Streptococcus, Haemophilus influenza, Staphylococcus, Klebsiella, anaerobes and enterococci. Staphylcocci is reported to be the most common $[2,6,8]$. The incidence of Pott's Puffy Tumor has further decreased with the advent of antibiotics, however has not been completely eradicated, its documentation exceedingly rare.

Diagnosis is primarily confirmed through the means of imaging, computed tomography (CT) and magnetic resonance imaging (MRI). CT will show an opacified frontal sinus with swelling of overlying bone. Focal abscess may also be seen, as well as complications that may extend further intracranially such as epidural abscess, subdural abscess, meningitis, cerebral abscess or dural sinus thrombosis, as a result of posterior spread of infection. These intracranial involvements can be more easily seen and delineated in MRI e.g. initial enhancement of dura mater, extraaxial fluid collection, cerebritis or cerebral 


\section{Open Access Journal of Neurology \& Neurosurgery}

abscess formation [3]. Intracranial abscesses are seen in $60 \%$ of patients. Preseptal and orbital cellulitis may also result due to direct downward spread of infection $[9,10]$. CT is useful mainly for planning treatment, and MRI is more helpful in identifying intracranial complications [11].

Management of condition is mainly through surgical intervention, specifically endoscopic sinus surgery and craniectomy, and usually requires both an otolaryngologist and a neurosurgeon to address the cranial and sinus aspects of the disease [6]. The objective of surgery is to drain the sinus and excise diseased bone and granulation tissue [12]. Intravenous antibiotic therapy is required post operatively, usually for 6-8 weeks. In most cases following treatment, patient is asymptomatic without neurological deficits [13].

Pott's Puffy tumor is usually considered a surgical emergency, however it can also be treated conservatively given the right context, as highlighted in this particular case. It is therefore paramount that the clinician be vigilant and informed of such treatment algorithms to avoid unnecessary surgical intervention.

\section{Case Report}

A 19-year-old male with a history of intermittent episodes of sinusitis and rhinitis, initially presented to clinic with rightsided frontal sinus pain, to which he was sent out on amoxicillin.
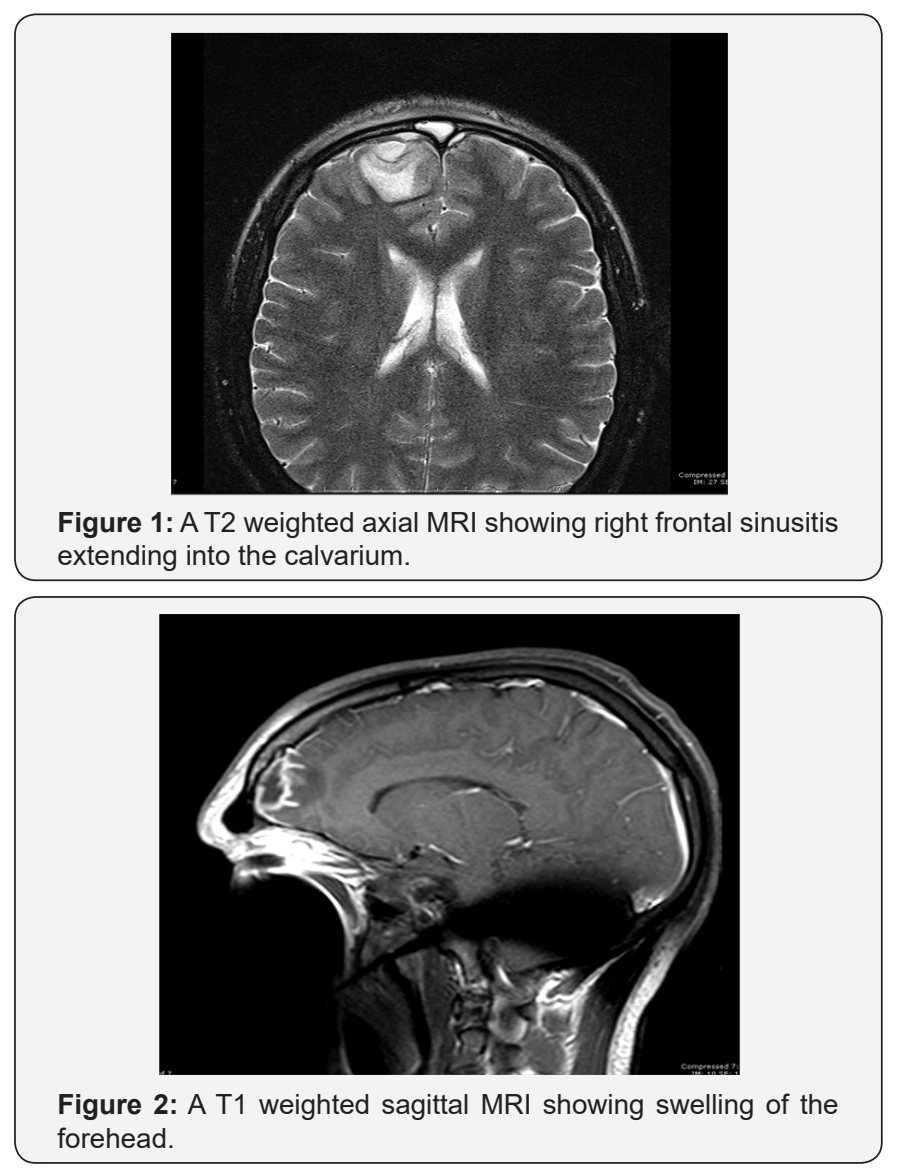

5 days later, patient returned, this time to the emergency room, with complaints of vomiting and weakness with sinus pressure. Sinus pain was rated at $8 / 10$ on pain scale. Forehead swelling, nasal obstipation, periorbital swelling (specifically around right eye), and new onset of headache particularly in the frontal area was also present, however no neurological deficits were noted. Patient could not open his right eye due to swelling.

Patient was treated with oral Augmentin without improvement. Patient was then started on broad-spectrum antimicrobial therapy geared towards organisms associated with sinusitis (e.g. Staphyloccous aureus/MRSA, Haemophilus, Streptococcus pneumonia, microaerophilic streptococci, and gram positive rods). This consisted of Rocephin, Vancomycin and Flagyladministered in appropriate doses. Patient was hydrated using IV fluids to treat nausea and given Zofran and oral pain medicines.

Imaging studies were conducted and showed what appeared to be an epidural collection in the frontal area, right frontal sinusitis, and ethmoid sinusitis with preseptal cellulitis and extension into epidural space in the frontal region. MRI showed paranasal sinus opacification with intracranial extension, extraaxial empyema formation, dural and leptomeningeal enhancement with some focal meningitis. These findings were consistent with Pott's puffy tumor, a rare syndrome associated with frontal sinusitis (Figure 1-3).

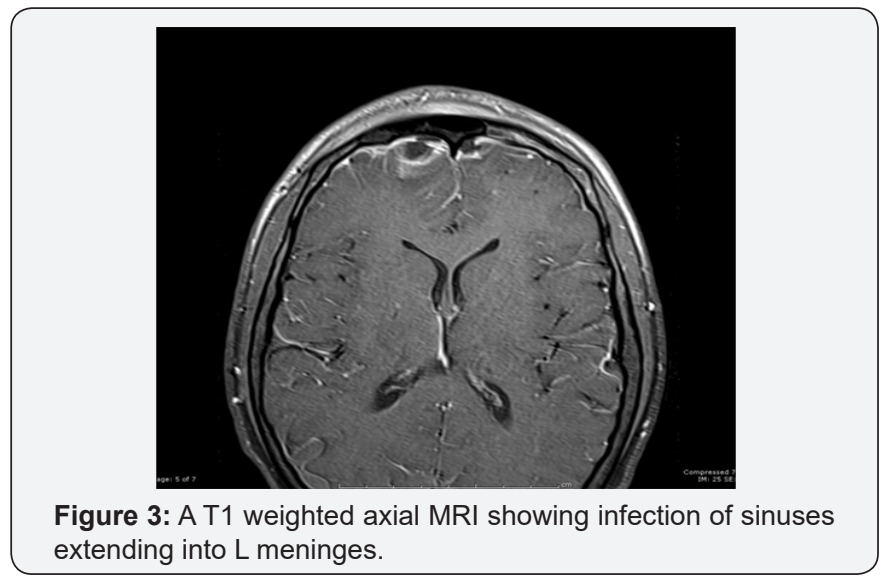

Patient received a bilateral sinusoto myendoscopically to drain as much empyema as possible. Patient was kept on broad spectrum antimicrobial therapy postoperatively and until complete resolution of findings. Neurosurgeon was consulted for potential cerebritis, and patient had a total of 3 MRIs, spaced 1-2 weeks apart, to track progress. Obvious clinical improvement was noted, though MRI scans showed slight progression of disease. Despite this, patient remained neurologically intact and headaches improved. Patient preferred to continue with IV antibiotics and avoid craniotomy. Patient was cautioned to report back if any new neurological symptoms were to manifest. Patient was discharged, and no surgical intervention was deemed necessary in subsequent follow-up visits. 


\section{Open Access Journal of Neurology \& Neurosurgery}

\section{Discussion}

Pott's Puffy Tumor is an extremely rare syndrome, consisting of one or more subperiosteal abscesses, seen usually as either a complication of frontal sinusitis or as an aftermath of head trauma. Formation of abscesses and osteomyelitis of frontal bone, trademarks of this condition, usually result from spread of infection through the venous drainage of the frontal sinus, from direct extension of the infection through the bone itself, or from direct contamination from penetrating trauma [7].

This condition is often unrecognized and difficult to diagnose based on clinical presentation. Frontal sinusitis is often silent, and if it manifests physically, is often presented by nonspecific symptoms such as headache, fever and nasal discharge [5,7]. Prompt diagnosis may facilitate conservative management of this condition [14].

It is observed predominantly in the adolescent population, though can also be seen in adults. This condition is a risk factor for intracranial complications such as subdural empyema and brain abscess, which have been reported in about $60-85 \%$ of patients, less so in adult than in pediatric cases [15]. The types of factors and conditions that predispose patients to such complications are not well understood.

In this particular case, the patient was in his late teens. This particular age period is particularly susceptible, because diplopic vein flow is more increased and a more loose connection exists between frontal sinuses as compared to in adults [15].

Traditionally, this condition entails exigent surgical management. The extent of surgical intervention is largely dependent on presence and progression of intracranial complications, necrosis of bone, and response to antibiotic therapy. All of these can be cycled back to timing of diagnosis. The floor of the frontal sinus comprises the roof of the orbit, and the posterior border of the frontal sinus, especially if inflamed, may impinge on the neighboring dura, increasing likelihood of intracranial complications [16]. To address the subsequent neurological symptoms and control spread of infection, a craniotomy with sinus and abscess drainage is usually required.

In this particular patient however, although prompt surgical drainage was instigated and patient had a sinus washout, patient recovered from empyema/cerebritis without craniotomy. Instead, patient was subjected to a rigorous antibiotic regimen that controlled infection and avoided the need to undergo neurosurgical intervention.

Typically, craniotomy is clearly indicated in the setting of empyema and extraaxial CNS infections. This surgical procedure allows for evacuation of pus and decompression of underlying cerebral hemisphere [11,14]. Antibiotic therapy is typically not enough to control infection, but in this particular case, institution of appropriate therapy was prompt, aggressive, and had broad spectrum activity leading to good central nervous system penetration and avoidance of late complications and extension of infection.
Rapid diagnosis, drainage of sinus and craniotomy for complete removal of pus, as well as appropriate antibiotic therapy comprise the treatment algorithm to ensure optimal outcome for this condition. This case report however highlights that medical management of this condition with minimal surgical treatment may be feasible if patient is monitored strictly for any worsening neurological sequelae and patient is placed under a strict antibiotic regimen.

\section{References}

1. Karaman E, Hacizade Y, Isildak H, Kaytaz A (2008) Pott's puffy tumor. The Journal of craniofacial surgery 19(6): 1694-1697.

2. Shehu BB, Mahmud MR (2008) Pott's puffy tumour: a case report. Annals of African medicine 7(3): 138-140.

3. Lang EE, Curran AJ, Patil N, Walsh RM, Rawluk D, et al. (2001) Intracranial complications of acute frontal sinusitis. Clinical otolaryngology and allied sciences. 26(6): 452-457.

4. Williams SP, Wilkie MD (2014) Pott's puffy tumour: an unforgettable complication of frontal sinusitis. BMJ Case Rep doi: 10.1136/bcr-2014204061.

5. Skomro R, McClean KL (1998) Frontal osteomyelitis (Pott's puffy tumour) associated with Pasteurella multocida-A case report and review of the literature. The Canadian journal of infectious diseases. Journal canadien des maladies infectieuses. Can J Infect Dis Mar 9(2): 115-121.

6. Suwan PT, Mogal S, Chaudhary S (2012) Pott's Puffy Tumor: An Uncommon Clinical Entity. Case reports in pediatrics 2012: 386104.

7. Feder HM, Cates KL, Cementina AM (1987) Pott puffy tumor: a serious occult infection. Pediatrics 79(4): 625-629.

8. Jung J, Lee HC, Park IH, Lee HM (2012) Endoscopic endonasal treatment of a Pott's Puffy Tumor. Clinical and experimental otorhinolaryngology 5(2): 112-115.

9. Nicoli TK, Makitie A (2014) Images in clinical medicine. Frontal sinusitis causing epidural abscess and puffy tumor. The New England journal of medicine 370(11): e18

10. Durur-Subasi I, Kantarci M, Karakaya A, Orbak Z, Ogul H, et al. (2008) Pott's puffy tumor: multidetector computed tomography findings. The Journal of craniofacial surgery 19(6): 1697-1699.

11. Kombogiorgas D, Solanki GA (2006) The Pott puffy tumor revisited: neurosurgical implications of this unforgotten entity. Case report and review of the literature. Journal of neurosurgery 105(2 Suppl): 143149.

12. Holder J, Corbin D, Marquez S, Clarke H, Walcott J, et al. (1991) Pott's puffy tumour and subdural empyema following frontal sinusitis. West Indian Med J Mar 40(1): 33-36.

13. Maheshwar AA, Harris DA, Al-Mokhthar N, Evans RA (2001) Pott's puffy tumour: an unusual presentation and management. J Laryngol Otol 115(6): 497-499.

14. Ketenci I, Unlu Y, Tucer B, Vural A (2011) The Pott's puffy tumor: a dangerous sign for intracranial complications. Eur Arch Otorhinolaryngol 268(12): 1755-1763.

15. Akiyama K, Karaki M, Mori N (2012) Evaluation of adult Pott's puffy tumor: our five cases and 27 literature cases. The Laryngoscope 122(11): 2382-2388.

16. Price A, Mohan A, Bush LM (2012) Acute sinusitis resulting in a craniotomy: an uncommon complication of a common infection. Case reports in infectious diseases 2012: 979836. 
This work is licensed under Creative

Commons Attribution 4.0 Licens

DOI: 10.19080/OAJNN.2017.03.555603
Your next submission with Juniper Publishers will reach you the below assets

- Quality Editorial service

- Swift Peer Review

- Reprints availability

- E-prints Service

- Manuscript Podcast for convenient understanding

- Global attainment for your research

- Manuscript accessibility in different formats ( Pdf, E-pub, Full Text, Audio)

- Unceasing customer service

Track the below URL for one-step submission https://juniperpublishers.com/online-submission.php 